\title{
Thrombocytopenia in dyschromatosis universalis hereditaria
}

\author{
S Pirasath ${ }^{1}$, T Sundaresan ${ }^{1}$, T Tamilvannan ${ }^{2}$
}

Ceylon Medical Journal 2012; 57: 124-125

\section{Introduction}

Dyschromatosis universalis hereditaria (DUH) is an extremely rare genodermatosis, characterised by hyperand hypo-pigmented macules forming a reticulate pattern. We describe a patient with features of DUH.

\section{Case report}

A 14-year old boy presented to causality medical ward with history of left side chest pain and asymptomatic progressive mottled pigmentation over the trunk and limbs, which had been noted since birth and had become more noticeable with age. There was no history of photophobia or photosensitivity. They were born to healthy, non consanguineous parents, following an uneventful pregnancy. His mother and mother's sister also had a similar appearance. Physical examination showed numerous asymptomatic, generalised hyperpigmented macules of 0.5 $\mathrm{cm}$ interspersed with spotty hypopigmented macules. The lesions were denser on the limbs (Figure1) than on the trunk (Figure 2). Mucosa was also involved (Figure 3). Palms and soles were not involved. The hair, nails and teeth appeared normal. There was no apparent atrophy, erythema or telangiectasia. Systemic examination did not show abnormalities. Biopsy from the hyperpigmented lesions revealed hyperpigmentation of basal and suprabasal cells, mild orthokeratosis and occasional melanophages with mild melanin incontinence suggestive of DUH (Figure 4). He also had severe thrombocytopenia, microcytic hypochromic anaemia, early signs of glaucoma and left side conduction deafness. Bone marrow biopsy revealed active megakaryopoiesis.
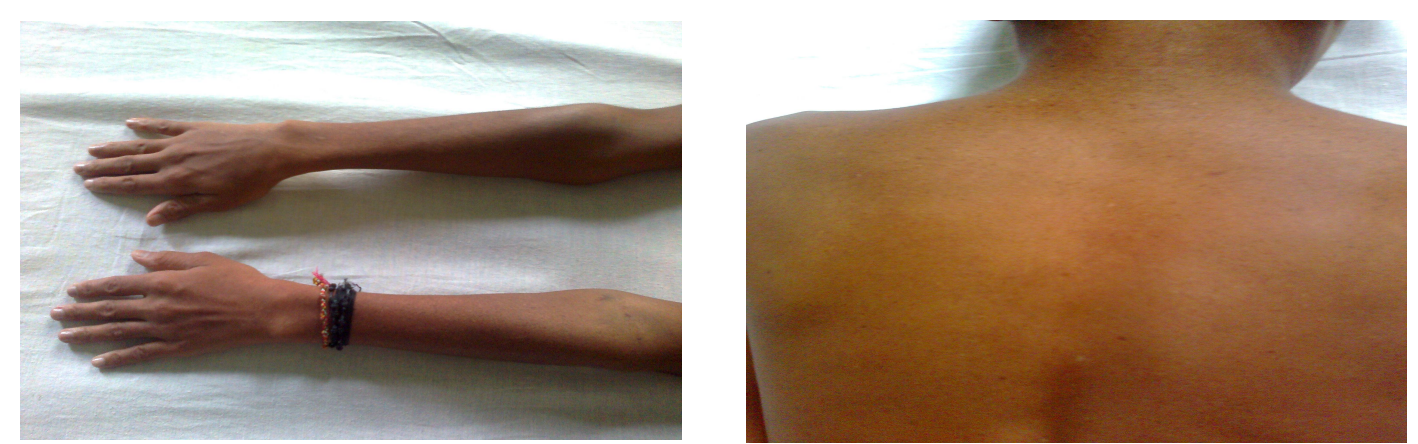

Figures 1 and 2. Hyper-pigmented macules interspersed with spotty hypo pigmented macules denser on the limbs (Figure 1) than on the trunk (Figure 2).

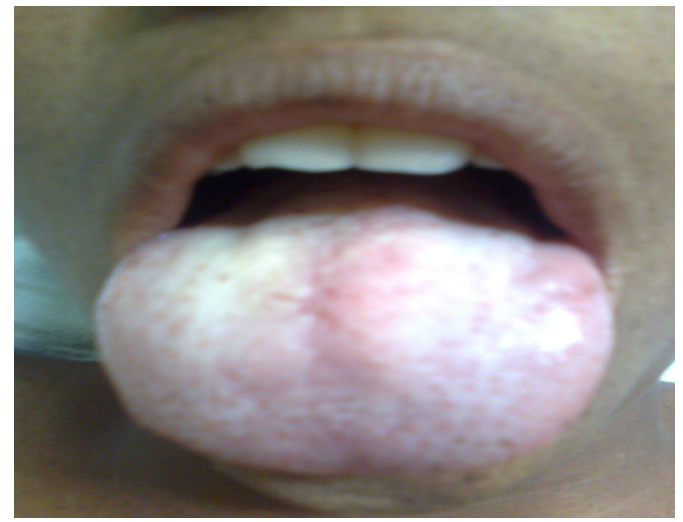

Figures 3. Hyper-pigmented macules interspersed with spotty hypo pigmented macules denser on the oral mucosa and tongue.

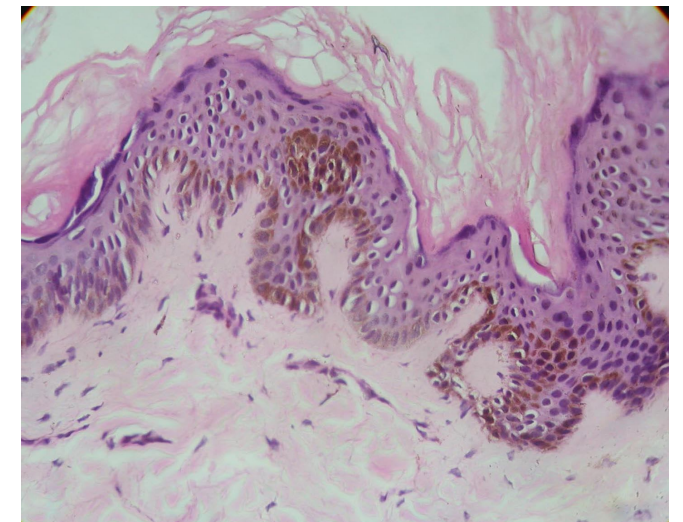

Figure 4. HE X100: The basal layer in the hyper pigmented lesions showed an increase in pigment along with melanin incontinence whereas the hypo pigmented lesions it showed a decrease in pigment.

${ }^{1}$ Medical and ${ }^{2}$ Dermatology Unit, Teaching Hospital, Batticaloa, Sri Lanka.

Correspondence: SP, e-mail: <selladuraipirasath81@gmail.com>. Received 8 November 2011 and revised version accepted 28 March 2012. Competing interests: none declared. 


\section{Discussion}

Two major types of DUH have been described, based on distribution of lesions: dyschromatosis universalis hereditaria (DUH), in which a mixture of hyper and hypopigmented macules occur all over the body presenting as a generalised leukomelanoderma with relative sparing of the face, palms, and soles and dyschromatosis symmetrica hereditaria (DSH), which is characterised by a symmetrical distribution of hyperpigmented and hypopigmented macules on the extremities $[1,2]$. Both conditions have been reportedly mostly fore Japan.

The aetiology of DUH is not known. It has been suggested that DUH is a disorder of the number of melanocytes. However, an electron microscopic study suggested that DUH may be a disorder of melanosome production in epidermal melanin units rather than a disorder of the number of melanocytes [3].

In DUH, skin lesions appear during the first few years of life. The trunk and extremities are the dominant sites. Facial lesions are uncommon. Involvement of palms and soles is unusual [4]. Abnormalities of hair and nails may occur.

The histopathology shows a focal increase or decrease in melanin content of the basal layer (depending on the type of the lesion biopsied) and occasionally pigmentary incontinence. In our case, histopathology of skin biopsy reveals hyperpigmentation of basal and suprabal cells, mild orthokeratosis, occasional melanophages and mild melanin incontinence (Figure 4). Number of melanocytes is within normal histological limits.

In this case, he has systemic manifestations such as severe thrombocytopenia, microcytic hypo chromic anaemia, early signs of glaucoma and left side conduction deafness. Thrombocytopenia has not been described as a feature of DUH before.

Generally, DUH does not progress or worsen with age. These is no definitive treatment for DUH. In our patient the disease has been stable for the past 14 years.

\section{References}

1. Ichikawa T, Higara Y. A propos d'une anomalie pigmentaire inédite. Japanese Journal of Dermatology 1933; 34: 360-4.

2. Toyama I. Dyschromatosis symmetrica herediteria. Japanese Journal of Dermatology 1929; 29: 95-6.

3. Kim NS, Im S, Kim SC. Dyschromatosis universalis hereditaria. Journal of Dermatology 1997; 24: 161-4.

4. Gharpuray MB, Tolat SN, Patwardham SP. Dyschromatosis: its occurrence in two Indian families with unusual features. International Journal of Dermatology 1994; 33: 391-2. 